\title{
Research on the Modes, Paths and Countermeasures of the Integrative Development of Guangzhou Internet and Cultural Industry
}

\author{
Weisha Cai ${ }^{1, a^{*}}$, Bin $\mathrm{Gu}^{2, \mathrm{~b},{ }^{*}}$ and Xingbiao Wang ${ }^{3, \mathrm{c}}$
}

${ }^{1}$ School of Economics and Commerce, South China University of Technology, 510006, Guangdong, China

${ }^{2}$ School of Economics and Commerce, South China University of Technology, 510006, Guangdong, China

${ }^{3}$ School of Economics and Commerce, South China University of Technology, 510006, Guangdong, China

a892111299@qq.com, b69985608@qq.com, c21398571@qq.com

Keywords: Internet industry, Cultural industry, Integrative development.

\begin{abstract}
With the development of Internet and cultural industry, Guangzhou formed three modes of the integrative development. According to the modes, the paper puts forward three paths of the integrative development of Guangzhou Internet and cultural industry, and three countermeasures combining with the paths, which are conducive to the integration of Guangzhou Internet and cultural industry.
\end{abstract}

\section{广州互联网与文化产业融合发展的模式、路径与对策研究}

\author{
蔡玮莎 $1, \mathrm{a}^{*}$ ，谷斌 $2, \mathrm{~b},{ }^{*}$ ，王兴标 $3, \mathrm{c}$ \\ 1华南理工大学经济与贸易学院, 广州市, 广东省, 中国 \\ 2华南理工大学经济与贸易学院, 广州市, 广东省, 中国 \\ 3华南理工大学经济与贸易学院, 广州市, 广东省, 中国 \\ a892111299@qq.com, b69985608@qq.com, c21398571@qq.com
}

关键词: 互联网产业; 文化产业; 融合发展

中文摘要. 随着互联网与文化产业的发展, 广州形成了融合发展的三大模式。根据这些模式, 本文提出广州互联网与文化产业融合发展的三大路径, 以及结合路径相应的三大对策, 有利 于促进广州的互联网与文化产业融合。

\section{1. 引言}

广州作为历史文化名城，一方面，其文化产业的整体实力和市场竞争力日益提高。《广 州文化创意产业发展报告（2016）》显示，广州文化产业增加值占 GDP的比例上升到 5.15\%, 规模在 2015 年达到 933 亿元。另一方面, 广州积极推进互联网与文化产业融合, 例如, 在 广播电视服务领域, 广州广播电视台推出掌中广视融媒体; 在文化创意设计领域, 欢聚时代 旗下的YY语音是大型娱乐资讯互动平台; 在网络游戏方面, 广州聚集了多益等著名公司。

互联网与文化产业融合是比较新的说法，目前国家从政策高度上予以重视，也有一些学 者对我国的互联网与文化产业融合发展进行了研究。赵爱玲等研究了互联网与文化产业融合 的动因、互动效应和对策建议 ${ }^{[1]}$ 。郭艳茹分析了互联网文化产业的数字化和海量内容等特点, 
以及对传统文化企业的影响和今后的发展思考 ${ }^{[2]}$ 。常凌肿指出互联网促进了文化产业的转型、 跨界融合和业态结构升级 ${ }^{[3]}$ 。但已有的研究很少是结合广州具体情况, 并且系统全面地分析 其互联网与文化产业融合的模式、对应的路径、又该作何对策的。

\section{2. 广州互联网与文化产业融合发展的模式}

产业融合模式包括重组型融合、渗透型融合和延伸型融合等 ${ }^{[4]}$ 。广州市的互联网与文化 产业融合发展，具体有以下几种融合发展模式。

\section{1 以文化信息传输为基础的产业升级融合模式}

这类融合模式以广播电视电影业最为明显，文化信息的存储和传输向数字化发展，互联 网文化产品也呈现数字化和虚拟现实化。广州积极推进三网融合, 广播电视通过互联网平台 实现了文化信息的传播。例如, 荔枝FM网络电台推出了APP, 用户通过移动互联网就可以录 制、编辑、上传、存储、收听、下载电台内容，实现了文化信息传输的网络化。

\section{2 以文化创意为基础的产业渗透融合模式}

这类融合模式以新闻出版业、文化创意设计类最为代表。新闻出版业由过去的纸质载体 转变为数字出版, 借助互联网可以进行多终端呈现更丰富的内容。文化创意设计类则围绕IP 研发形成了以数字动漫、网络游戏、文化产品APP等多种产业形态融合的产品。例如，广州 日报通过微信公众号推出微报纸和图文信息。广州的星光侠VR体验馆则推出了9D的VR游戏。

\section{3 以文化生产为基础的电子商务融合模式}

这类融合模式以文化实物产品生产的文化产业为代表，包括工艺美术品、文化用品、文 化专用设备等的产品生产。文化产业通过电子商务模式构建新的展示和销售渠道, 搭建企业 管理信息化。例如，广州包装集团通过设立 “人印人爱” 网络相册印制的天猫电商等平台来 打造互联网个性化定制文印产品，并为客户提供在线咨询等服务。

\section{3. 广州互联网与文化产业融合发展的路径}

广州应该结合自身优势，设计互联网与文化产业融合发展的有效路径。

\section{1 谋篇布局，做好文化产业与互联网融合发展的顶层设计}

依托国家大力实施 “互联网+” 和 “创新驱动发展” 的战略背景，广州应该针对性地做好 文化产业与互联网产业融合发展的顶层设计，推进 “互联网+文化产业” 行动计划。例如, 按 照《广州市国民经济和社会发展第十三个五年规划纲要》的要求, 设计好文化电商、创意设 计、网游动漫、数字出版、网络视频、无线音乐等互联网文化产业新业态的发展方向。

\section{2 产业联动, 打造互联网文化全产业链和产业融合网}

互联网与文化产业本身都是包容性很强的产业，产业融合呈现模糊化、无边界化的特点。 因此, 广州要加快以文化产业作为主导产业链, 将互联网产业融合到文化产业的各个环节和 要素, 延生新的商业价值和商业模式。以IP等文化内容创意为开发核心, 通过大数据、云计 算、VR等技术贯穿于创意生成、产品开发、知识产权保护、营销推广和客户消费等产业价值 链环节, 打造电影舞剧、数字出版、动漫电竞、网络游戏、衍生玩具等实现多产业联动、满 足消费者多元互动需求的产业融合网。

\section{3 内外互动, 借助互联网文化走向全国和世界}

首先，互联网与文化产业融合具有共享化的特点，体现在资源、渠道、流程、人才和市 场等各方面的共享; 也具有数字化和网络化带来的资源分布的地域离散性和网络联结状。广 州作为国际化大都市，可以利用共享经济时代的互联网和文化资源，将互联网与文化产业融 
合发展中的优势企业或环节的资源进行整合。其次，不同国家或地区的文化不同，广州既要 开发具有岭南本土特色的文化产品, 又要处理好本地文化基因与外部文化的关系, 借助互联 网传播广的特点结合不同受众群体的文化消费特征进行产品研发和市场挖掘, 形成内外互动。

\section{4. 广州互联网与文化产业融合发展的对策}

\section{1 加快改革，促进产业融合结构升级}

\subsection{1 加快文化体制改革, 激发互联网创意活力}

文化部《2016年文化系统体制改革工作要点》中，要求用创新性举措推动文化产业结构 优化升级，这从国家层面给互联网与文化产业融合发展提供了政策支持。广州市应以互联网 与文化产业融合为突破口，推进文化产业的机制体制改革，破除不利于新技术、新产业发展 的机制障碍, 紧跟科技前沿, 抢占文化产业创新制高点。加大对互联网技术的引进利用, 通 过融入VR、AR、直播、人工智能、营销云等技术，拓展文化产品的形态和体验，激发互联 网创意的活力。

\section{1 .2 突出发展重点, 依托重点产业带动融合发展}

广州的文化产业与互联网产业融合发展要优先培育重点产业和骨干企业。重点发展网络 游戏、数字动漫、网络电视、新媒体等文化产业, 用互联网相关技术推进广播、电视、电影 等产业结构的升级, 以带动其他相关产业发展。要进一步推进三网融合, 促进互联网与电视、 电信的融合，增强互联网基础资源供给。

4.1.3 科学规划园区, 以科技企业带动文化产业融合升级

产业融合在确定发展重点产业后，要科学规划文化科技产业园区。广州已有一些文化创 意园区, 未来还可以科学布局产业结构, 引进创新能力强的文化科技企业加入到产业园区, 建设互联网文化产业卵孚化平台, 通过设立创新基金, 引导科研机构和高校等将已有的科研成 果、互联网文化创意等带到文化科技创业园进行孵化。

\section{2 做好服务, 营造优良的互联网文化创新空间}

\subsection{1 强化队伍建设, 激发创新活力}

文化产业与互联网产业呈现双向融合的特点，广州虽有较多的文化产业从业人员，但需 要既懂文化产业又具备互联网思维或技术的从业人员。一是要扩大产业和地域范围引进交叉 复合型骨干人才，以骨干人才带建团队。二是依托广州高校的人才培养优势，将其与产业规 划等联系起来，建立实训基地和项目孵化基地，投入资金，鼓励大学生参与项目和创业。 4.2.2 完善配套措施, 汇集创意力量

在《广州文化产业实施办法》等的基础上，广州应该继续积极实施财政扶持、知识产权 保护、鼓励原创内容等支持互联网与文化产业融合发展的相关配套举措。例如, 按照税收优 惠政策对文化科技企业纳税减免等，对科技文化企业进行政策引导；加大对互联网文化产业 的知识产权保护力度，建立维权中心，严厉打击侵权行为，创造公平有序的创意环境。

\subsection{3 健全激励机制, 创造产业精品}

互联网与文化产业融合的产品或服务包含着科技与创新的思维和智慧。广州可以通过构 建健全的激励机制和轻松的创新环境来激发人力资源的潜能, 创造出科技含量高的新产品。 可以通过设立特别奖项，职称评定等激发企业创新人员的积极性，对促进互联网与文化产业 融合的个人、企业等组织给予一定奖励，鼓励企业以发明专利入股做股权激励等。

\section{3 强化保障, 贯彻产业融合目标任务}

\subsection{1 加强组织领导, 明确目标任务}

广州要促进互联网与文化产业的融合发展，首先要将其作为政府重点战略工作；其次， 在制定好相关政策措施后，应加强对政策的贯彻落实的领导，按照既定的目标路线强化责任 分工和落实; 最后, 需要多组织、多部门、跨领域的协同合作, 因此, 还需要做好沟通工作。 


\subsection{2 大力宣传引导，推动全面参与}

促进互联网产业融合文化产业发展，推进广州城市的文化科技建设，需要形成良好的群 众基础和市场基础。可以通过线上线下多渠道开展互联网与文化产业融合的宣传推广工作， 做好文化科技产品、公益性文化科技服务的宣传、体验、应用推广等工作，开展互联网文化 产品进校园、社区等公共场所, 让群众对VR、可穿戴设备等更加了解, 适当平衡天河等中心 城区与从化等郊区的互联网文化资源, 营造良好的互联网文化氛围 ${ }^{[5]}$, 促进互联网文化消费。 4.3.3 保障资金投入，拓宽融资渠道

加大广州对互联网与文化产业融合的企业的财政支持力度是强化保障的有效措施。一方 面, 以市级财政为主, 将年度的部分研发投入（R\&D）重点支持互联网与文化产业融合的发 展项目, 加大对企业、科研机构从事互联网文化创新科研活动的支持力度。另一方面, 要通 过引进社会资本参与到相关的创新活动中, 以风险投资、股权投资、网络众筹等多种合作模 式多方筹集资金，促进广州互联网与文化产业的深度融合发展。

\section{5. 结束语}

广州作为具有文化底蕴的城市，文化产业作为支柱产业继续扩大发展规模，互联网等技 术也领先, 两者的产业融合发展形成了一定的模式, 需要通过特定的路径和一些政策来推进。 未来，随着大数据、云计算、人工智能和更多高科技的发展, 以及群众对文化休闲娱乐等精 神体验和享受需求的增加, 广州的互联网与文化产业融合将进一步发展。

\section{致谢}

本文为广州市社科院项目《互联网与文化产业融合发展研究及对广州启示》 (2015WHJD03), 广州市软科学研究专项《广州市促进信息消费政策研究》(201510020008), 国家社科基金项目《虚拟社区知识组织研究》(12BTQ041)的阶段性成果之一。

\section{References}

[1] Zhao Ailing and Chen Xuemei, Research on the integrative development of cultural industry and Internet industry, Co-Operative Economy \& Science, vol.4, pp. 22-24, 2016.

[2] Guo Yanru, A joint economic-lot-size model for purchaser and vendor, Business, vol.46, pp. $278,2015$.

[3] Chang Lingchong, Integrative development of cultural industry boosted by Internet, Journal of Beifang University of Nationalities (Philosophy and Social Science), vol.2, pp. 96-101, 2014.

[4] Feng Xiaotang, Research review on the integrative development of cultural industry and related industries, China Market, vol. 4, pp. 75-77, 2014.

[5] Chen Libing, Analysis on the development direction and path of Guangzhou network culture industry, Academic Search for Truth and Reality, vol. 155, pp. 107-108, 2013. 